\title{
PENGARUH LATIHAN DUMBELL-THERA BAND TERHADAP DAYA TAHAN OTOT LENGAN DAN AKURASI MEMANAH PADA ATLET PANAHAN
}

\author{
Betrix Teofa Perkasa Wibafied Billy Yachsie \\ Fakultas Ilmu Keolahragaan, Universitas Negeri Yogyakarta, Jl. Colombo No. 1, Karangmalang Depok, Sleman, \\ Yogyakarta, Indonesia \\ betrixteofa.2019@student.uny.ac.id
}

\begin{abstract}
Abstrak
Program latihan Dumbell-Thera Band kepada atlet panahan Kabupaten Banyumas di teliti karena ada beberapa pelatih dan atlet masih belum mengerti mengenai tujuan diberikannya latihan Dumbell- Thera Band. Penelitian ini bertujuan untuk mengetahui pengaruh latian dumbell-thera band terhadap daya tahan otot lengan dan akurasi memanah pada atlet panahan Kabupaten Banyumas. Desain penelitian ini adalah penelitian eksperimen. Metode yang digunakan adalah penelitian eksperimen semu. Disain yang digunakan dalam penelitian ini dengan menggunakan rancangan "One Group Pretest-Posttest Design. Instrumen yang digunakan adalah tes dan pengukuran akurasi dengan cara memanah jarak 30 meter dan daya tahan otot lengan menggunakan alat ukur Holding Bow Test. Populasi dalam penelitian ini adalah atlet maupun pengurus panahan Kabupaten Banyumas yang berjumlah 85 orang dengan sampel dalam penelitian ini berjumlah 12 orang. Teknik analisis data menggunakan uji $t$ paired sample t test. Hasil penelitian dan pembahasan sebelumnya dapat diperoleh nilai uji t pada akurasi memanah diketahui nilai t hitung $(9,869)>t$ tabel $(1,80)$ dan uji t pada Daya Tahan Otot Lengan diperoleh nilai thitung $(8,812)$ $>\mathrm{t}$ tabel $(1,80)$. Dengan demikian, dapat disimpulkan ada pengaruh latihan dumbell-thera band terhadap daya tahan otot lengan dan akurasi memanah pada atlet panahan Kabupaten Banyumas.
\end{abstract}

Kata Kunci: Dumbell-Thera Band, Daya Tahan Otot Lengan, Akurasi Memanah

\section{EFFECTS OF DUMBBELL-THERA BAND EXERCISE TOWARDS THE ARM MUSCLE ENDURANCE AND ARCHERY ACCURACY IN ARCHERY ATHLETES}

\begin{abstract}
The Dumbell-Thera Band training program for Banyumas Regency archery athletes was examined because there are several trainers and athletes who still do not understand the purpose of the DumbellThera Band training. This study aims to determine the effect of dumbbell-thera band exercises on arm muscle endurance and archery accuracy in archery athletes in Banyumas Regency The design of this research is experimental research. The method used is quasi-experimental research. The design used in this study using the design of "One Group Pretest-Posttest Design. The instrument used was a test and measurement of accuracy by arching a distance of 30 meters and endurance of the arm muscles using a measuring instrument Holding Bow Test. The population in this study were 85 athletes and administrators of Banyumas Regency with 12 people as the sample in this study. The data analysis technique used paired sample t test. The results of previous studies and discussions can be obtained $t$ test value on archery accuracy known $t$ count value (9.869)> t table (1.80) and t test on Arm Muscle Endurance obtained $t$ value (8.812)> t table (1.80). Thus, it can be concluded that there is an influence of dumbbell-thera band exercises on arm muscle endurance and archery accuracy in Banyumas Regency archery athletes.
\end{abstract}

Keywords: Dumbell-Thera Band, Arm Muscle Endurance, Archery Accuracy 


\section{MEDIKORA, Vol. XVIII No. 2 Oktober 2019 - 80}

Betrix Teofa Perkasa Wibafied Billy Yachsie

\section{PENDAHULUAN}

Panahan merupakan suatu cabang olahraga yang mempunyai karakteristik tersendiri dibandingkan cabang olahraga lainnya, meskipun dalam perkembangannya kurang diminati oleh masyarakat, tetapi akhir-akhir ini olahraga panahan mulai di minati seluruh masyarakat Indonesia. Sejarah munculnya panahan, menurut Harsono (2004:1) orang hanya bisa mengiraira sejak kapan panahan mulai ada. Orang purbakala telah menggunakan busur dan panah untuk berburu dan mempertahankan hidup sejak 100.000 tahun yang lalu. Dalam ajang pertandingan bergengsi Presiden Joko Widodo juga memberikan kejutan memanah pada pesta pembukaan Asian Para Games 2018 di Stadion Utama Gelora Bung Karno bersama seorang anak perempuan penyandang disabilitas.

Pada dasarnya cabang olahraga panahan merupakan gabungan antara olahraga dan seni. Disebut olahraga karena menggunakan otot-otot fungsional, seperti trapezius, tricep dan deltoid dan juga membutuhkan ketahanan fisik. Disebut seni karena membutuhkan sentuhan jiwa yang halus, kesabaran, keuletan dan ketahanan mental (Nawir, 2011: 123). Faktor-faktor seperti konsentrasi, koordinasi, kekuatan, reaksi, daya tahan, keseimbangan, kekuatan otot tangan dan daya tahan otot lengan sangat menentukan dalam menghasilkan teknik dasar memanah yang baik dan benar. Dalam cabang olahraga panahan hasil penampilan dan prestasi dapat terlihat pada skor yaitu jumlah perkenaan anak panah pada target face atau sasaran.

Dalam olahraga panahan di Indonesia ada 4 divisi/ronde, yaitu divisi recurve, divisi compound, divisi nasional, dan divisi tradisional, adapun divisi recurve dan compound adalah yang diperlombakan sampai kejuaraan dunia bahkan olympic games dan divisi nasional dan tradisional hanya diperlombakan kancah tertinggi adalah PON. Dilihat dari karakteristiknya olahraga panahan adalah melepaskan panah melalui lintasan tertentu menuju sasaran pada jarak tertentu. Apabila diperbandingkan dengan olahraga yang memerlukan gerak statis atau suatu keterampilan tertutup lainnya seperti cabang olahraga menembak, perbedaan panahan dengan menembak terletak pada jenis kekuatan dorongannya dan alat yang digunakan.

Keberhasilan atlet dipengaruhi oleh sejumlah faktor yang saling mendukung antara faktor yang satu dengan lainya. Faktor tersebut berasal dari dalam maupun dari luar atlet itu sendiri yang meliputi faktor fisik, psikis, teknik, taktik, pelatih, sarana dan prasarana latihan, latihan, sosial, dan sebagainya. Pada penelitian ini peneliti akan melakukan pengamatan latihan panahan Beji di Kecamatan Kedungbanteng, Kabupaten Banyumas, yang nantinya akan dijadikan sebagai tempat penelitian dan sekaligus sebagai objek penelitian. Peneliti menemukan bahwa minat atlet terhadap olahraga panahan pada pusat latihan panahan Beji di Kecamatan Kedungbanteng sangat tinggi, akan tetapi dalam pengamatan peneliti masih banyak kekurangan pada atlet-atlet panahan ronde nasional di pusat latihan panahan Beji di Kecamatan Kedungbanteng, yaitu kurangnya penguasaan daya tahan otot lengan dan akurasi memanah.

Bagi seorang atlet, faktor yang terpenting dalam menunjang keberhasilan serta prestasi adalah meningkatkan teknik-teknik dasar memanah. adapun teknik memanah menurut Achmad Damiri dalam jurnal Yudik Prasetyo (2013: 1-10) pada dasarnya ada sembilan langkah, yaitu : Sikap Berdiri (stand). Memasang Ekor Panah (nocking). Mengangkat Lengan Busur Setengah Tarikan (Set Up). Menarik Tali Busur (drawing). Menjangkarkan Lengan Penarik (anchoring). Menahan Sikap Panahan (holding). Membidik (Aiming). Melepas Tali/Panah (release). Menahan Sikap Panahan dan Gerak Lanjut (follow throught).

Berbeda dengan cabang olahraga lain pada umumnya panahan mengukur hasil aktivitasnya pada obyek tertentu, panahan mengacu pada bentuk gerak yang dikerjakan dengan kombinasi terpadu dan menjelma dari setiap bagian anggota tubuh dari komponen-komponen kemampuan motorik seperti: kekuatan, keseimbangan, reaksi, dan ketepatan. Dengan koordinasi yang sesuai dan tata urutan gerak yang selaras akan terbentuk rangkaian gerak artistik yang berpengaruh pada ketepatan memanah. Berdasarkan dari beberapa komponen kondisi fisik yang mendukung kemampuan memanah dan berdasarkan pada pengamatan dan 
pengalaman penulis sebagai atlet panahan, penulis menekankan faktor kondisi fisik yang menunjang keberhasilan kemampuan memanah dilihat dari beberapa unsur kondisi fisik yang berhubungan dengan kemampuan memanah.

Menurut penulis faktor kondisi fisik yang paling dominan dalam menunjang kemampuan memanah yaitu kekuatan otot lengan dan kestabilan karena dalam memanah membutuhkan ketenangan dan akurasi yang tinggi agar melepas anak panah tepat pada sasaran. Munawar, (2003: 21) menyatakan bahwa daya tahan otot lengan adalah sekelompok otot untuk melakukan kontraksi secara berturut-turut (contohnya push up\&wirst curl) dan mampu mempertahankan kontraksi statis dalam jangka waktu yang lama (contohnya pull up). Daya tahan otot lengan merupakan komponen utama cabang olahraga panahan, memegang busur panahan dengan kuat tetapi tetap rilek merupakan peranan yang sangat signifikan dan merupakan unsur utama dari semua komponen memanah, khususnya komponen otot lengan yang menunjang dalam keberhasilan memanah. Dengan otot lengan yang kuat, seorang pemanah akan dapat menarik serta meregangkan busur panah dengan tarikan yang maksimal dengan demikian dapat membuat anak panah melaju lebih cepat tepat pada sasaran. Kurnia (2017: 32) menyatakan akurasi dalam olahraga panahan adalah tingkat kedekatan perkenaan anak panah hasil tembakan dari pemanah ke titik X dalam target yang berwarna kuning (nilai 10).

Thera band merupakan langkah latihan awal untuk pemula atau pemanah yang akan naik tingkatnya ke divisi recurve maupun compund agar mengurangi cidera pada saat memanah yang sesungguhnya. Latihan ini mengajarkan anda untuk membayangkan sedang menarik busur dengan benar dari posisi awal samapi akhir. Teknik membayangkan menarik busur yang di ganti dengan thera band yang benar akan memberikan dampak kestabilan yang lebih baik dan mencegah cedera pada bahu Anda selama proses latihan memanah pada jangka waktu yang lama. Mulailah latihan ini terlebih dahulu melalui prosedur dan latihan "Set, Set-up". Lalu ulangi gerakan menarik seperti pada saat stand, set-up, drawing, anchoring, holding, aiming, release. Ulangi 15-20X (repetisi), istirahat sejenak, lalu ulangi latihan ini minimal 5 kali (Set) (Ceri Ann Davies, 2015: 18).

Berdasarkan pengamatan penulis pada saat memberi program latihan Dumbell-Thera Band kepada atlet panahan Kabupaten Banyumas ada beberapa pelatih dan atlet masih belum mengerti mengenai tujuan diberikannya latihan Dumbell-Thera Band. Kurangnya pemahaman variasi latihan kondisi fisik untuk cabang olahraga panahan dari beberapa atlet ada yang bermalas-malasan, kemudian masih ada atlet yang pada saat memanah dia merasakan tremor di tangan kiri oleh karena itu tremor yang dia alami akan berpengaruh terhadap groping anak panah yang menyebabkan kurangnya tingkat akurasi memanah yang di sebabkan tremor dan ada juga yang tidak mau melakukan latihan yang diberikan, karena bagi beberapa pelatih dan atlet yang senior mereka menganggap bahwa latihan kondisi fisik untuk cabang panahan hanya di lapangan dengan menembakkan anak panah sebanyak-banyaknya. Tetapi membuat pemanah melakukan teknik yang baik dan hasil yang stabil pelatih harus memberikan latihan kondisi fisik yang tepat dengan menggunakan variasi latihan yang tepat dan tidak membosankan. Posisi tubuh yang tepat akan menambah tingkat konsentrasi yang tinggi sehingga pada saat sikap holding (sikap memanah) akan memberikan efek yang tenang pada saat angin besar datang, pada saat aiming (membidik) tangan pun tidak akan terbawa angin karena tubuh memiliki keseimbangan yang tinggi dan proses release (melepaskan anak panah) memberikan hasil yang maksimal. Karena kurangnya pengetahuan pelatih maupun atlet tentang variasi latihan untuk cabang panahan, maka dari itu penulis membuat penelitian berjudul Pengaruh Latihan Dumbell-Thera Band Terhadap Daya Tahan Otot Lengan dan Akurasi Memanah Pada Atlet Panahan Kabupaten Banyumas. 


\section{METODE}

Penelitian ini adalah penelitian eksperimen semu yang dimaksudkan untuk mengetahui ada tidaknya akibat dari "sesuatu" yang dikenalkan pada subyek selidik (Suharsimi, 2005:07). Penelitian ini masuk dalam bentuk one group pretest-postest design, yaitu eksperimen yang dilaksanakan pada satu kelompok eksperimen dengan diberikan perlakukan berupa latihan Dumbell-Thera Band tanpa kelompok pembanding. Metode Latihan Dumbell-Thera Band adalah salah satu bentuk latihan fisik dengan menggunakan variasi dari Dumbell dan Thera Band yang bermanfaat untuk melatih kemampuan daya tahan otot lengan dan akurasi memanah Latihan ini menggunakan 5 Set dan 15-20 repetisi, setiap repetisi menarik Thera Band dan menahan Dumbell selama 15-30 detik, jadi setiap melakukan 1 kali repetisi pada saat menarik Dumbell-Thera Band yang telah mencapai posisi engker maka mulailah di tahan 15-30 detik, recovery pada setiap repetisi dua kali lipat dari waktu yang digunakan saat menahan busur.

\section{HASIL DAN PEMBAHASAN}

Deskripsi hasil penelitian data pretest dan posttest pada daya tahan otot lengan dan akurasi memanah pada atlet panahan dapat dideskripsikan sebagai berikut:

\section{Hasil data akurasi memanah pada atlet panahan Kabupaten Banyumas}

Hasil penelitian data akurasi memanah pada atlet panahan Kabupaten Banyumas dapat dilihat pada tabel dibawah ini :

Tabel 1. Data Akurasi Memanah

\begin{tabular}{|c|c|c|}
\hline Responden & Pretest & Posttest \\
\hline 1 & 319 & 330 \\
\hline 2 & 325 & 336 \\
\hline 3 & 311 & 326 \\
\hline 4 & 308 & 316 \\
\hline 5 & 297 & 299 \\
\hline 6 & 286 & 300 \\
\hline 7 & 271 & 282 \\
\hline 8 & 188 & 205 \\
\hline 9 & 218 & 231 \\
\hline 10 & 317 & 326 \\
\hline 11 & 304 & 313 \\
\hline 12 & 316 & 328 \\
\hline Mean & 288,33 & 299,33 \\
\hline Median & 306 & 314,5 \\
\hline Mode & 188 & 326 \\
\hline Std. Deviation & 43,07 & 41,41 \\
\hline
\end{tabular}

\section{Hasil data daya tahan otot lengan atlet panahan Kabupaten Banyumas}

Hasil penelitian data daya tahan otot lengan atlet panahan Kabupaten Banyumas dapat dilihat pada tabel dibawah ini: 
MEDIKORA, Vol. XVIII No. 2 Oktober 2019 - 83

Betrix Teofa Perkasa Wibafied Billy Yachsie

Tabel 2. Data Daya Tahan Otot Lengan

\begin{tabular}{|c|c|c|}
\hline Responden & Pretest & Posttest \\
\hline 1 & 30,57 & 37,91 \\
\hline 2 & 32,57 & 39,67 \\
\hline 3 & 22,05 & 25,22 \\
\hline 4 & 20,77 & 28,04 \\
\hline 5 & 26,54 & 30,07 \\
\hline 6 & 15,24 & 22,88 \\
\hline 7 & 14,21 & 25,39 \\
\hline 8 & 11,67 & 18,15 \\
\hline 9 & 18,82 & 22,09 \\
\hline 10 & 22,39 & 27,11 \\
\hline 11 & 19,13 & 25,23 \\
\hline 12 & 28,51 & 32,64 \\
\hline Mean & 21,87 & 27,87 \\
\hline Median & 21,41 & 26,25 \\
\hline Mode & $11,67^{\mathrm{a}}$ & $18,15^{\mathrm{a}}$ \\
\hline Std. Deviation & 6,61 & 6,33 \\
\hline
\end{tabular}

\section{Hasil uji hipotesis dengan uji t}

Uji t dalam penelitian ini dimaksudkan untuk menjawab hipotesis yang telah diajukan. Uji hipotesis menggunakan uji-t (paired sample $t$ test) pada taraf signifikan $5 \%$. Hasil uji hipotesis (uji-t) dapat dilihat pada tabel di bawah ini:

Tabel 4. Hasil Uji Hipotesis (Uji t)

\begin{tabular}{|l|r|c|c|c|c|}
\hline \multicolumn{1}{|c|}{ Pretest - posttest } & Df & T tabel & T hitung & P & Sig 5 \% \\
\hline Akurasi Memanah & $\mathbf{1 1}$ & $\mathbf{1 , 8 0}$ & $\mathbf{9 , 8 6 9}$ & $\mathbf{0 , 0 0 0}$ & $\mathbf{0 , 0 5}$ \\
\hline Pengaruh Daya Tahan Otot Lengan & $\mathbf{1 1}$ & $\mathbf{1 , 8 0}$ & $\mathbf{8 , 8 1 2}$ & $\mathbf{0 , 0 0 0}$ & $\mathbf{0 , 0 5}$ \\
\hline
\end{tabular}

Berdasarkan analisisi data Akurasi Memanah diperoleh nilai t hitung $(9,869)>t$ tabel $(1,80)$, dan nilai $\mathrm{p}(0,000)<$ dari 0,05 , hasil tersebut menunjukkan bahwa nilai t hitung lebih besar dari pada t tabel. Dengan demikian diartikan ada pengaruh latihan dumbell-thera band terhadap akurasi memanah pada atlet panahan Kabupaten Banyumas. Sedaangkan data Daya Tahan Otot Lengan diatas diperoleh nilai t hitung $(8,812)>\mathrm{t}$ tabel $(1,80)$, dan nilai $\mathrm{p}(0,000)<$ dari 0,05 , hasil tersebut menunjukkan bahwa nilai t hitung lebih besar dari pada t tabel. Dengan demikian dapat diartikan ada pengaruh latihan dumbell-thera band terhadap daya tahan otot lengan pada atlet panahan Kabupaten Banyumas. Berdasarkan hasil dari kedua uji t tersebut menunjukan jika nilai $\mathrm{t}$ hitung $>\mathrm{t}$ tabel, dengan hasil tersebut menunjukan hipotesisnya diterima, sehingga hipotesisnya berbunyi "ada pengaruh latihan dumbell-thera band terhadap daya tahan otot lengan dan akurasi memanah pada Atlet Panahan Kabupaten Banyumas"

Olahraga panahan tidak banyak menuntut keterampilan gerak. Panahan sejatinya merupakan olahraga yang sederhana. Untuk mendapatkan akurasi yang tinggi, perlu adanya konsistensi. Dalam olahraga panahan akurasi / ketepatan adalah komponen yang harus dimiliki oleh seorang atlet agar dapat menedapatkan sasaran yang baik saat memanah. Panahan biasanya dilakukan ditempat terbuka dan harus steril dari kegiatan apapun, karena anak panah sifatnya tajam dan apabila mengenai sesuatu akan mengakibatkan kerusakan dan jika terkena manusia atau hewan dapat menyebabkan cidera atau trauma yang mendalam bagi korbannya. Di Penelitian kali ini penulis akan meneliti tentang pengaruh latihan Dumbell-Thera Band 


\section{MEDIKORA, Vol. XVIII No. 2 Oktober 2019 - 84}

Betrix Teofa Perkasa Wibafied Billy Yachsie

terhadap daya tahan otot lengan dan akurasi memanah, yang diharapkan dalam penelitian kali ini, atlet di Kabupaten Banyumas dapat referensi tentang aspek latihan fisik.

Dalam mendapatkan akurasi dapat didukung dengan fisik yang prima seorang pemanah dalam melakukan tembakan harus memenuhi beberapa aspek yaitu (1) Teknik yang baik, (2) Fisik yang baik, (3) Mental yang baik. Di Indonesia ketiga aspek tersebut masih kurang maksimal yang dilaksanakan oleh atlet, karena masih ada pelatih yang tidak memahami tentang 3 aspek tersebut untuk menuju akurasi yang baik. Biasanya pelatih hanya memberikan aspek yang pertama yaitu aspek teknik sedangkan aspek fisik dan mental masih kurang dalam memberikan pengetahuan, apabila aspek kedua dan ketiga tidak dilaksanakan atlet akan kurang maksimal dalam menghadapi perlombaan yang menyebabkan rasa lelah saat menarik busur, tremor pada lengan kiri, grogi atau minder dalam saat bertanding dan biasanya menyebabkan seorang atlet mengalami kekalahan. Sehingga dibutuhkan kekuatan lengan untuk menarik tali busur, dan juga daya tahan lengan untuk menahan anak panah sebelum dilepaskan agar anak panah dapat melesat sesuai sasaran yang diinginkan. Oleh karena itu, dibutuhkan latihan untuk meingkatkan daya tahan lengan dan tingkat akurasi dalam memanah, salah satunya dengan Latihan Dumbell-Thera Band.

Latihan Dumbell-Thera Band adalah sebuah sistem latihan yang menggunakan variasi alat antara dumbell dan Thera Band agar memudahkan saat latihan fisik atau pengganti latihan pada saat tidak mengunakan busur dan anak panah yang diperkuat oleh jurnal seorang mantan atlet olimpiade dari USA yaitu Jake Kaminski (15 Mei 2017) yang pernah melakukan penelitian tentang bow training. Jake mengatakan bahwa dalam bow training lebih efektif untuk sistem latihan dibandingkan latihan memanah seperti biasa, kemudian dari pendapat itu Jake menarik kesimpulan untuk menggabungkan latihan biasa dengan bow training. Apabila memanah biasa sehari maksimal bisa melepaskan 300 anak panah, maka apabila digabungkan dengan bow training satu jam sehari bisa melepaskan 500 anak panah, jadi dengan banyaknya menembakan anak panah dalam sehari akan menambah daya tahan otot lengan atau stabilitas dalam memanah.

Pada dasarnya latian Dumbell-Thera Band mengacu dan memodifikasi latihan bow training agar memudahkan seorang atlet pemula/profesional yang belum memiliki busur panah atau dari divisi standar bow/nasional akan berganti ke divisi recurve maupun compund agar masih tetap bisa latihan awalan untuk memperkuat daya tahan otot lengan agar pada saat mengunakan busur yang sesungguhnya tidak merasa lelah dan tremor, karena pada divisi recurve dan compund lebih berat dari busur nasional/standar bow. Latihan dumbell-thera band sangat efektif di lakukan pada saat latihan fisik yang dapat dilakukan dimana saja tanpa harus memerlukan lapangan yang luas untuk berlatih. Tatacara latihan Dumbell-Thera Band hampir sama pada saat memanah dengan busur panah, namun tidak mengunakan busur dan anak panah dengan mengganti Dumbell sebagai busur (hendel) dan Thera Band sebagai setring untuk di tarik. Berdasarkan pada uji t menunjukan jika nilai thitung $>\mathrm{t}$ tabel, dan hipotesisnya diterima, sehingga hipotesisnya berbunyi "ada pengaruh latihan dumbell-thera band terhadap daya tahan otot lengan dan akurasi memanah pada atlet panahan Kabupaten Banyumas".

Tujuan dari sebuah latihan adalah untuk meningkatkan prestasi agar terampil dan hasil dari latihan seorang atlet dapat maksimal, dengan adanya arahan dari pelatih untuk mencapai tujuan umum latihan. Selain teknik yang benar setiap pemanah harus memiliki kondisi fisik dan daya tahan otot lengan yang bagus, jika kondisi fisik dan komponen daya tahan otot lengan seseorang pemanah baik maka dapat mempengaruhi performa seorang atlet panahan dan akan mempermudah dalam mempelajari teknik pada keterampilan memanah yang lebih kompleks. Pentingnya daya tahan otot lengan dan akurasi memanah khususnya di dalam cabang olahraga panahan adalah karena panahan dilakukan dalam waktu yang cukup lama, maka dengan memiliki daya tahan otot lengan yang baik akan membantu kestabilan pada saat memanah yang menyebabkan akurasi memanah semakin tinggi dan mendapatkan poin sempurna. Dengan 
demikian, latihan dumbell-thera band meningkatkan daya tahan otot lengan dan akurasi memanah, hasil tesebut mengindikasikan bahwa antar daya tahan otot lengan dan akurasi memanah saling berkaitan serta saling berpengaruh terhadap kestabilan seorang atlet panahan. Oleh karena itu, untuk mendapatkan akurasi yang baik, maka seorang pemanah harus mempunyai daya tahan otot lengan yang baik. Dari hal-hal tersebut, latihan yang di lakukan secara rutin sangat dibutuhkan agar kemampuan dalam memanah terlatih dengan baik dan stabil.

\section{SIMPULAN}

Daya tahan otot lengan adalah otot yang berkontraksi secara berulang-ulang dengan beban tertentu serta dalam jangka waktu yang lama dan dalam penelitian ini dibuktikan dengan menahan tarikan busur dengan waktu yang ditentukan pada masing-masing individu. Sedangkan akurasi memanah adalah seorang atlet yang menembakan anak panah sebanyak 6 kali, selama 6 seri/rambahan dan dengan jumlah total 36 anak panah. Anak panah tersebut ditembakan ke arah bantalan yang sudah ada face target nilai pada jarak 30 meter, dan selanjutnya dihitung total nilai seluruh anak panah yang menancap di face target. Berdasarkan hasil penelitian dan pembahasan sebelumnya dapat diperoleh : uji t pada akurasi memanah diketahui nilai $\mathrm{t}$ hitung $(9,869)>\mathrm{t}$ tabel $(1,80)$ dan uji t pada Daya Tahan Otot Lengan diperoleh nilai $\mathrm{t}$ hitung $(8,812)>\mathrm{t}$ tabel $(1,80)$, Dengan demikian dapt disimpulkan ada pengaruh latihan dumbell-thera band terhadap daya tahan otot lengan dan akurasi memanah pada atlet panahan Kabupaten Banyumas.

\section{DAFTAR PUSTAKA}

Davies A C. (2015). National Talent Development Programme Talent Guide 2015-2017. Inggris: Archery GB. Lilleshall National Sports Centre.

Harsono. (1988). Coaching dan Aspek Psikologis dalam Coaching. Jakarta: CV.Tambal Kurnia.

Kurnia Dwi Aryani. (2017). pengaruh plank exercise terhadap daya tahan otot lengan dan akurasi memanah pada siswa sekolah dasar di Kota Yogyakarta. Yogyakarta: UNY

Nawir, Nukhrawi. 2011. Kontribusi Kekuatan Otot Tangan Dan Daya Tahan Otot Lengan Dengan Kemampuan Memanah Jarak 30 Meter Pada Atlet Panahan Sulawesi Selatan (Jurnal). Sulawesi Selatan: FIK UNM. Praktek. Jakarta: Rineka Cipta.

Munawar Furqon dan Agus Kristiyanto. (2003) Prediksi Prestasi Panahan Ronde Nasional Berdasarkan Daya Tahan Otot Lengan, Ketajaman Penglihatan, dan Kecemasan pada Atlet PPLP Panahan Jawa Tengah. Tesis. UNS.

Riko Adi Baskoro. (2018) Pengaruh Bow Training Terhadap Daya Tahan Otot Lengan Dan Akurasi Memanah Anggota UKM Panahan UNY. Yogyakarta.

Suharjana. (2013). Kebugaran Jasmani. Yogyakarta: Jogja Global Media.

Suharjana. (2007). Latihan Beban. Yogyakarta: FIK UNY.

Sukadiyanto. (2011). Pengantar Teori dan Metode Melatih Fisik. Bandung: Lubuk Agung.

Sukadiyanto. (2002). Teori dan Metodologi Melatih Fisik Petenis. Yogyakarta:

Fakultas Ilmu Keolahragaan UNY

Yudik Prasetyo. (2011). Olahraga Panahan. Yogyakarta: CV Grafina Mediacipta.

http://itawaka.blogspot.co.id/2008/08/motor-learning-dalam-memanah.html (Situs ini diakses pada tanggal 18 febuari 2019 pada pukul 14.00). 